\title{
Nifedipine stimulates proliferation and migration of different breast cancer cells by distinct pathways
}

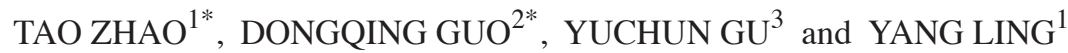 \\ ${ }^{1}$ Changzhou Tumor Hospital Affiliated of Suzhou University, Changzhou, Jiangsu 213000; \\ ${ }^{2}$ School of Life Sciences, Beijing University of Chinese Medicine, Beijing 100029; ${ }^{3}$ Laboratory of \\ Molecular Pharmacology, Institute of Molecular Medicine, Peking University, Beijing 100871, P.R. China
}

Received March 1, 2016; Accepted February 23, 2017

DOI: $10.3892 / \mathrm{mmr} .2017 .6818$

\begin{abstract}
Nifedipine is widely used to treat high blood pressure and angina. Were nifedipine able to promote the proliferation and migration of breast cancer, it would pose a significant threat for patients. Thus, it is important to determine the effects of nifedipine on breast cancer and the mechanism involved. The present study identified that nifedipine significantly promoted the proliferation and migration of breast cancer cells in vitro. The mechanism of nifedipine on different breast cancer cells was investigated and it was identified that the effects of nifedipine on MCF-7 cells were via the protein kinase $\mathrm{B}$-endothelial constitutive nitric oxide synthase-nitric oxide axis, and on MDA-MB-231 cells via activation of the extracellular signal-regulated kinase pathway. These results identified the distinct pathways in the activation of cell proliferation and migration presented in different cell lines by nifedipine. The present study advises that nifedipine can promote breast cancer and should be avoided for women who suffer from breast cancer and hypertension.
\end{abstract}

\section{Introduction}

Worldwide, breast cancer is the leading type of cancer in women, accounting for $25 \%$ of all cases (1). Genetic predisposition is the main reason for breast cancer (2-4).

There are three types of calcium channel blockers (CCBs), including dihydropyridine, phenylalkylamine and benzothiazepine. Nifedipine is the most common kind of CCB and is used to treat high blood pressure and angina. It has been reported that CCBs may be associated with cancer; a meta-analysis of

Correspondence to: Dr Yang Ling, Changzhou Tumor Hospital Affiliated of Suzhou University, 68 Honghe Road, Changzhou, Jiangsu 213000, P.R. China

E-mail: ycgu@pku.edu.cn

${ }^{*}$ Contributed equally

Key words: nifedipine, breast cancer cells, protein kinase B, extracellular signal-regulated kinases
17 observational studies identified that the long-term use of CCBs appears to have a significant association with breast cancer (5). The use of particular types of antihypertensive medications, including immediate-release CCBs and certain diuretics, may increase the risk of breast carcinoma among women aged between 65 and 79 years (6). Use of antihypertensive medication for $\geq 5$ years, compared with no use, was associated with a modest increased risk of invasive breast cancer $(\mathrm{RR}=1.18,95 \% \mathrm{CI}, 1.02-1.36)$ (7). In addition, a previous study of the authors (8) demonstrated that nifedipine could promote the proliferation and migration of breast cancer cells in vivo and in vitro. Others have considered that CCBs have no association with cancer (9). Patients with coronary heart disease (CHD) and treated with CCBs exhibited a similar risk of cancer incidence and total and cancer-related mortality as those not treated with CCBs (10). No statistically significant association was observed between the use of CCBs and breast cancer in 49,950 women in North Jutland (11). A mixed treatment comparison meta-analysis of randomized, controlled (placebo, active or untreated control) trials of antihypertensive drugs was conducted to determine the association between commonly used antihypertensive agents and the incidence of cancer and the results demonstrated that commonly used antihypertensive drugs were not associated with an increased chance of developing cancer (12).

Nifedipine is widely used in clinics, so it is important to determine its effects on breast cancer and the mechanism involved. The present study identified and confirmed that nifedipine can promote breast cancer in vitro. In MCF-7 cells, the effects of nifedipine are via the protein kinase $\mathrm{B}$ (Akt)-endothelial constitutive nitric oxide synthase (eNOS)-nitric oxide (NO) axis. However, nifedipine exercises its effects upon MDA-MB-231 cells via activation of the extracellular signal-regulated kinases (ERK) pathway.

\section{Materials and methods}

Cell culture and reagents. MCF-7 and MDA-MB-231 cells were purchased from the Cell Bank of the Chinese Academy of Sciences (Shanghai, China). MCF-7 cells were cultured in Dulbecco's Modified Eagle's medium (PromoCell GmbH, Heidelberg, Germany) containing $10 \%$ fetal bovine serum (FBS; Gibco; Thermo Fisher Scientific, Inc., Waltham, MA, 
USA) at $37^{\circ} \mathrm{C}$ in a humidified atmosphere of $95 \%$ air and 5\% $\mathrm{CO}_{2}$. MDA-MB-231 cells were grown in L15 medium (PromoCell $\mathrm{GmbH}$ ) containing $10 \% \mathrm{FBS}$ at $37^{\circ} \mathrm{C}$ in a humidified atmosphere of $100 \%$ air.

Other reagents purchased were nifedipine (Sigma-Aldrich; Merck KGaA, Darmstadt, Germany), MTT $(5 \mathrm{mg} / \mathrm{ml}$; Sigma-Aldrich; Merck KGaA), paraformaldehyde (4\%; Beijing Solarbio Science \& Technology Co., Ltd., Beijing, China), Crystal violet $(0.1 \%$, Beijing Solarbio Science \& Technology Co., Ltd.), radioimmunoprecipitation assay (RIPA) buffer (Beijing Solarbio Science \& Technology Co., Ltd.), phenylmethylsulfonyl fluoride (Beijing Solarbio Science \& Technology Co., Ltd.), protease inhibitor (25x; Roche Applied Science, Penzberg, Germany) and dimethylsulfoxide (DMSO; Sigma-Aldrich; Merck KGaA).

Proliferation assays. For the determination of cell proliferation, an MTT assay was conducted, as reported previously (8). MCF-7 and MDA-MB-231 cells were seeded at a density of 1,000 cells/well in 96-well plates. Following a 1 day incubation, the culture medium was replaced with new medium containing nifedipine or the same concentration of DMSO as control. The cells were incubated for 2 further days. Next, $10 \mu \mathrm{l}$ MTT was added for $3 \mathrm{~h}$. Then the culture medium was removed and $150 \mu \mathrm{l}$ of DMSO was added per well. The absorbance was measured at $540 \mathrm{~nm}$ using a Multiskan microplate reader (Thermo Fisher Scientific, Inc.).

Cell migration assays. For Transwell migration assays, harvested cells $\left(1 \times 10^{5}\right.$ cells) supplemented with $100 \mu 1$ serum-free medium were replated onto the upper chamber (a $6.5 \mathrm{~mm}$ polycarbonate membrane with $8.0 \mu \mathrm{m}$ pores; Corning Incorporated, Corning, NY, USA). DMEM and L15 medium containing $10 \%$ FBS was used as the chemoattractant and added to the lower well of the plate. Non-migrating cells were removed from the upper chamber using a cotton applicator. Migrating cells on the underside of the filter were stained with $0.1 \%$ crystal violet for 20 min and then were eluted by $33 \%$ glacial acetic acid. Optical density values were read by a Multiskan microplate reader (Thermo Fisher Scientific, Inc.) at $595 \mathrm{~nm}$.

Immunoblotting. Nifedipine was used to stimulate the breast cancer cells (MCF-7 cells, $10 \mu \mathrm{M}$; MDA-MB-231 cells $1 \mu \mathrm{M}$ ). Cells were lysed in RIPA buffer containing protease and phosphatase cocktails (Roche Applied Science). Equal amounts of protein $(50 \mu \mathrm{g})$ were separated by $10 \%$ SDS-PAGE and electro-transferred onto a PVDF membrane (Merck KGaA). Membranes were blocked with 5\% non-fat milk powder in TBST $(0.1 \%$ Tween-20 in $1 \mathrm{X}$ TBS) for $1 \mathrm{~h}$ at room temperature and then incubated with appropriate primary antibodies at $4^{\circ} \mathrm{C}$ overnight, followed by incubation with horseradish peroxidase-conjugated secondary antibodies for $1 \mathrm{~h}$ at room temperature. The following antibodies were used: Rabbit anti-P (Ser473)-Akt (1:1,000, no. 9271), rabbit anti-Akt (1:1,000, no. 9272), rabbit anti-P (Thr202/Tyr204)-ERK (1:1,000, no. 9101), mouse anti-ERK (1:1,000, no. 4696), all purchased from Cell Signalling Technology Inc. (Danvers, MA, USA), and mouse anti- $\beta$-actin $(1: 5,000$, no. M009; Beijing TDY Biotech Co., Ltd., Beijing, China).
Statistical analysis. All data were derived from $\geq 3$ independent experiments. Statistical analyses were conducted using SPSS version 19.0 (IBM SPSS, Armonk, NY, USA). Values were calculated as mean \pm standard error of the mean. Significant differences between the groups were determined using the unpaired one-way analysis of variance test. $\mathrm{P}<0.05$ was considered to indicate a statistically significant difference.

\section{Results}

Nifedipine promoted the proliferation and migration of breast cancer cells in vitro. Nifedipine as a CCB is commonly used in clinic to treat angina and hypertension. MCF-7 breast cancer cells were treated with nifedipine at the dosages of $1 \mu \mathrm{M}$ and $10 \mu \mathrm{M}$. Nifedipine at these two dosages significantly stimulated the proliferation of MCF-7 cells, when compared with control cells (Fig. 1A; P<0.01). Consistently, nifedipine at a dosage of $1 \mu \mathrm{M}$ also significantly exhibited a similar stimulation on the proliferation of MDA-MB-231 breast cancer cells, compared with the control group (Fig. 1B; $\mathrm{P}<0.01$ ). Nifedipine at a dosage of $10 \mu \mathrm{M}$ significantly promoted the migration of MCF-7 cells compared with control cells (Fig. 1C; $\mathrm{P}<0.05$ ). In addition, nifedipine $(1 \mu \mathrm{M})$ exhibited a similar stimulation on the migration of MDA-MB-231 cells (Fig. 1D; P<0.05).

Nifedipine stimulation effect on breast cancer cells not via its blockage on calcium channels. To test whether the stimulatory effect of nifedipine on breast cancer cells is due to alternation of the concentration of the intracellular free $\mathrm{Ca}^{2+}$, the MCF-7 and MDA-MB-231 cells were preincubated in the presence of $1 \mu \mathrm{M}$ nifedipine in DMEM or L15 medium for $1 \mathrm{~h}$ at $37^{\circ} \mathrm{C}$ and then loaded with Fura-8 (AAT Bioquest, Inc., Sunnyvale, CA, USA). No significant increase in $\left[\mathrm{Ca}^{2+}\right]_{i}$ was observed with either nifedipine alone or by increasing $\mathrm{K}^{+}$concentration from $2.5 \mathrm{mM}$ to $90 \mathrm{mM}$, indicating that MCF-7 and MDA-MB-231 cells did not express a functional L-type calcium channel. It suggested that the effect of nifedipine on the breast cancer cells was not due to calcium channels and cellular $\mathrm{Ca}^{2+}$ levels (data not shown).

Verapamil had no effect on the tumor growth in vitro. To test whether the stimulation of breast tumor is nifedipine-specific, another $\mathrm{CCB}$, verapamil, was used to treat MCF-7 and MDA-MB-231 breast cancer cells. No significant change in cell proliferation and migration was observed, indicating that the specific effects of nifedipine on MDA-MB-231 cells were not a common characteristic of L-type CCBs (data not shown).

Nifedipine effect upon MCF-7 cells not via ERK pathway. In our previous study (8), nifedipine could stimulate the ERK pathway of MDA-MB-231 cells. Notably, no differences in phosphorylation of ERK and total ERK were observed in MCF-7 cells with or without nifedipine at 10, 20, 40 and $60 \mathrm{~min}$. Membranes were reprobed for b-actin for loading control (Fig. 2A). No differences were observed in phosphorylation of ERK and total ERK in MCF-7 cells with or without nifedipine at $48 \mathrm{~h}$. Membranes were reprobed with $\beta$-actin for loading control (Fig. 2B). 
A

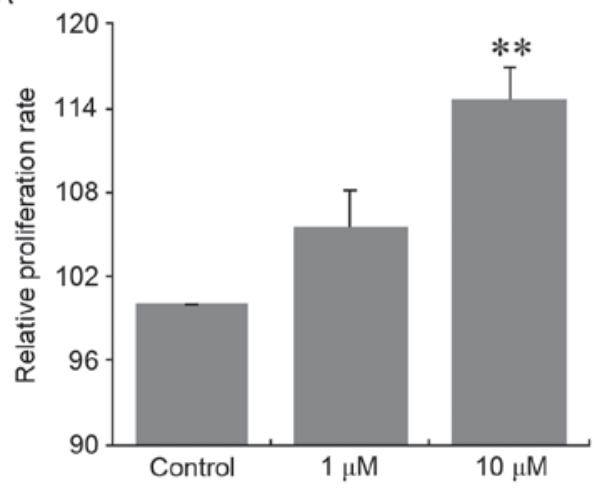

C

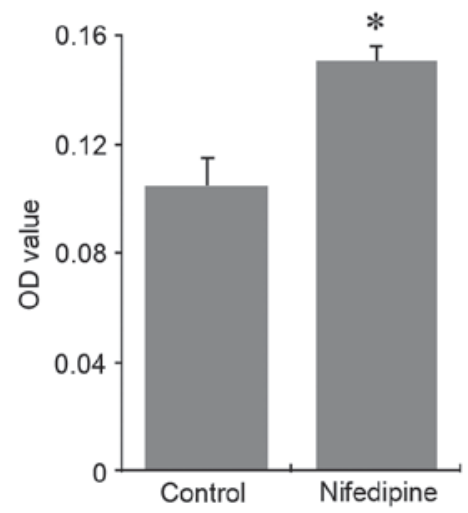

B

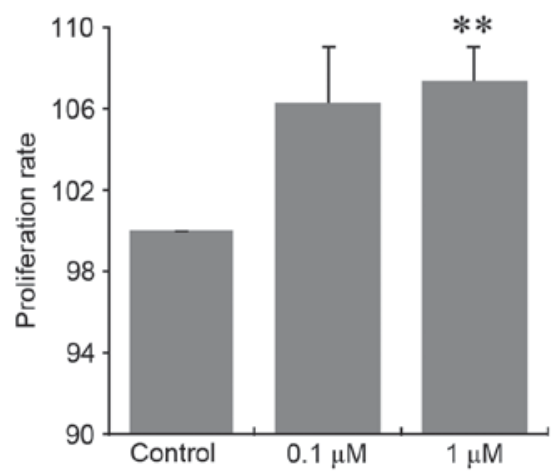

D

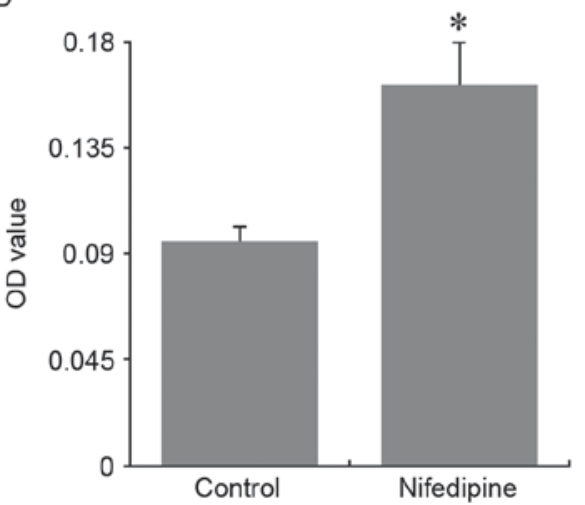

Figure 1. Nifedipine promoted the proliferation and migration of breast cancer cells in vitro. (A) $1 \mu \mathrm{M}$ and $10 \mu \mathrm{M}$ of nifedipine can stimulate the proliferation of MCF-7 cells. Results represent mean \pm SEM from three independent experiments. (B) $1 \mu \mathrm{M}$ and $10 \mu \mathrm{M}$ of nifedipine can stimulate the proliferation of MDA-MB-231 cells. Results represent mean + SEM from three independent experiments. (C) Nifedipine $(10 \mu \mathrm{M})$ promoted the migration of MCF-7 cells. Results represent mean \pm SEM from three independent experiments. (D) Nifedipine $(1 \mu \mathrm{M})$ promoted the migration of MDA-MB-231 cells. Results represent mean \pm SEM from three independent experiments. ${ }^{*} \mathrm{P}<0.05,{ }^{* *} \mathrm{P}<0.01$ vs. Control. OD, optical density; SEM, standard error of the mean.

A

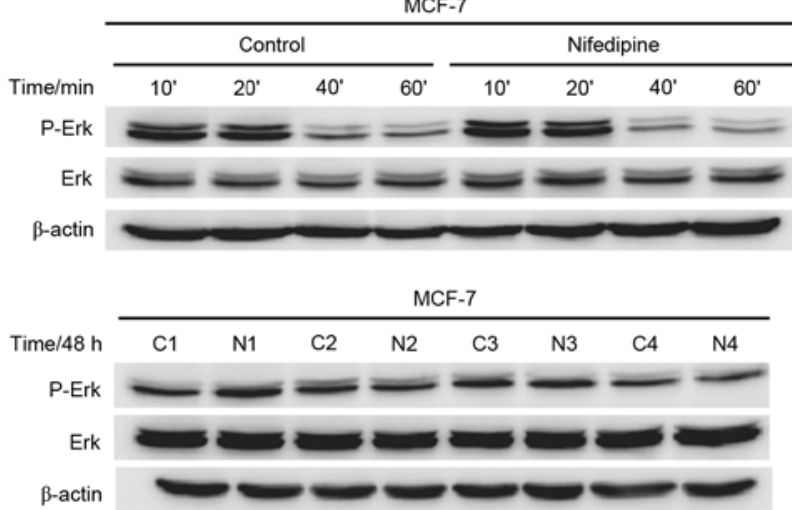

Figure 2. ERK pathway has no change in nifedipine treated MCF-7 cells. (A) Phosphorylated ERK (P-ERK) and total ERK immunoblotting in MCF-7 cells with or without nifedipine treatment at 10, 20,40 and $60 \mathrm{~min}$. Membranes were reprobed for $\beta$-actin for loading control. (B) p-ERK and total ERK immunoblotting in MCF-7 cells with or without nifedipine treatment at $48 \mathrm{~h}$. Membranes were reprobed for $\beta$-actin for loading control. Samples 1-4, repeats. C, control; N, nifedipine; ERK, extracellular signal-regulated kinases.

Akt activation in nifedipine treated MCF-7 cells. Notably, Nifedipine increased phosphorylation of Akt and total Akt following treatment at 5, 10, 20 and $40 \mathrm{~min}$. Membranes were reprobed for $\beta$-actin for loading control (Fig. 3A). Nifedipine also increased phosphorylated eNOS (P-eNOS) and total
eNOS in MCF-7 cells at 10, 20, 40 and 60 min. Membranes were reprobed for $\beta$-actin for loading control (Fig. 3B). These results suggested that nifedipine stimulated $\mathrm{MCF}-7$ cells via the Akt-eNOS-NO axis.

Nifedipine effect on MDA-MB-231 cells via ERK activation not Akt pathway. Nifedipine increased the phosphorylation of ERK in MDA-MB-231 cells following treatment at 10, 20, 40 and 60 min compared with the control groups, respectively. The p-ERK level at 10 min demonstrated the strongest stimulatory effects of nifedipine, and these decreased over time. Membranes were reprobed for $\beta$-actin for loading control (Fig. 4A). However, nifedipine had no effect on the phosphorylation of Akt in MDA-MB-231 cells. Membranes were reprobed for $\beta$-actin for loading control (Fig. 4B).

\section{Discussion}

In the present study, nifedipine was identified to significantly stimulate the proliferation and migration of $\mathrm{MCF}-7$ and MDA-MB-231 breast cancer cells. This stimulatory effect was nifedipine specific and verapamil, another calcium channel blocker, demonstrated no observable effect on the breast cancer cells. Notably, nifedipine effects upon MCF-7 cells were via the axis Akt-eNOS-NO while its effects upon MDA-MB-231 cells were via activation of ERK. The p-ERK level at $10 \mathrm{~min}$ exhibited the strongest stimulatory effects of 
A

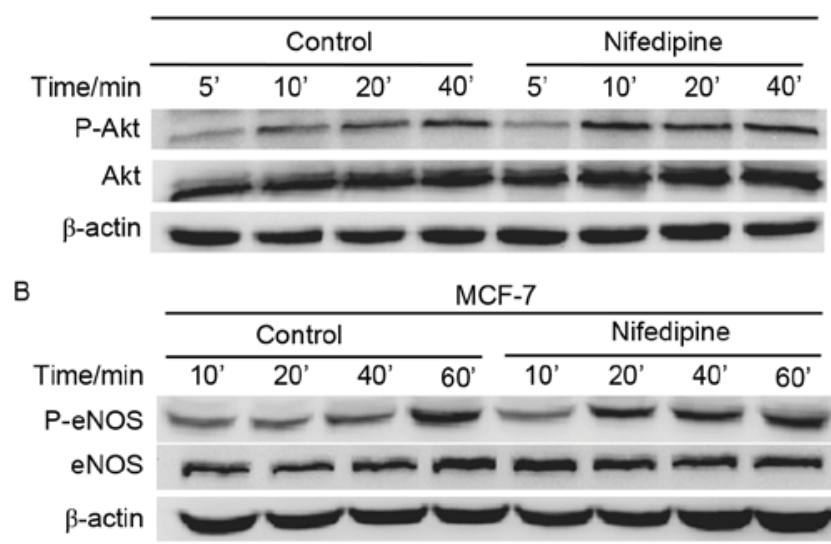

Figure 3. Akt activation in nifedipine treated MCF-7 cells. (A) p-Akt and total Akt immunoblotting in MCF-7 cells with or without nifedipine treatment at 5,10,20 and $40 \mathrm{~min}$. Membranes were reprobed for $\beta$-actin for loading control. (B) p-eNOS and total eNOS immunoblotting in MCF-7 cells treated with or without nifedipine treatment at 10, 20, 40 and $60 \mathrm{~min}$. Membranes were reprobed for $\beta$-actin for loading control. Akt, protein kinase B; eNOS, endothelial constitutive nitric oxide synthase.

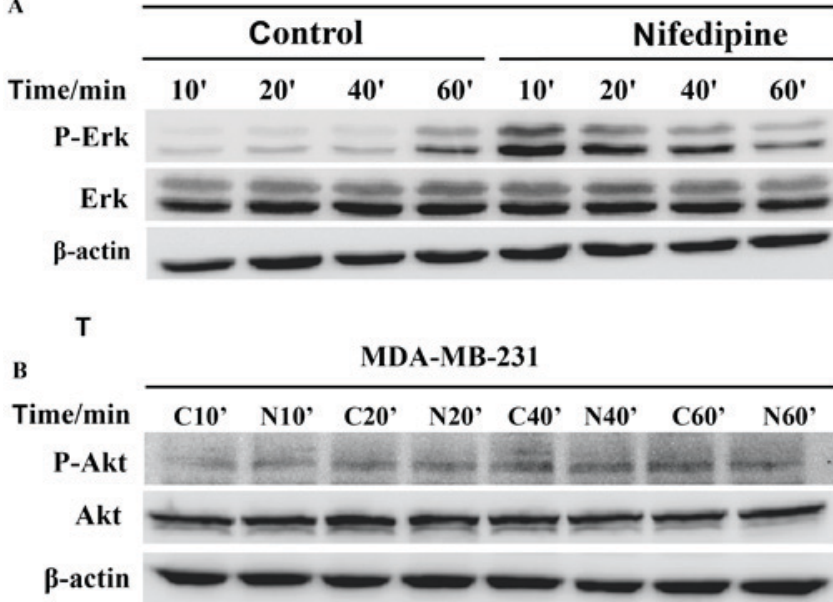

Figure 4. P-ERK activation and no change in Akt pathway in nifedipine treated MDA-MB-231 cells. (A) p-ERK immunoblotting in MDA-MB-231 cells with or without nifedipine treatment at 10,20,40 and $60 \mathrm{~min}$. Membranes were reprobed for $\beta$-actin for loading control. (B) p-Akt immunoblotting in MDA-MB-231 cells with or without nifedipine treatment at 10 , 20, 40 and $60 \mathrm{~min}$. Membranes were reprobed for $\beta$-actin for loading control. $\mathrm{C}$, control; N, nifedipine; ERK, extracellular signal-regulated kinases; Akt, protein kinase $\mathrm{B}$.

nifedipine and decreased over time, demonstrating a transient activation that has been reported elsewhere (13). These results suggested distinct pathways in activation of cell proliferation and migration presented in different cell lines by the same stimulator. Additionally, the present study advises that nifedipine promotes breast cancers and that nifedipine ought to be avoided in clinical practice, particularly for women who suffer from breast cancer and hypertension.

MCF-7 (14,15) and MDA-MB-231 (16) cells are derived from invasive ductal breast carcinoma and represent metastasis (pleural effusion) tumor type without ERBB2 amplification. However, there are distinct differences in the expression of estrogen receptor (ER), progesterone receptor and TP53 mutation between them. ER expression is one of most important criteria to distinguish the breast cancer type. Therefore, MCF-7 and MDA-AB-231 cells were utilized in the present study to understand the collective effects of nifedipine on breast cancer.

Previous studies on whether CCBs promote cancer cells are controversial $(5,17)$. The present study confirmed nifedipine as one of the $\mathrm{CCBs}$ that can potentiate breast cancer, although it is inconsistent with previous studies that this effect is nifedipine specific (18). With respect to the possible mechanism, $\left[\mathrm{Ca}^{2+}\right]_{\mathrm{i}}$ modulation was excluded by the evidence that MCF-7 and MDA-MB-231 cells do not express the CACNA1C and CACNA1D subtypes and $1 \mu \mathrm{M}$ nifedipine failed to alter $\left[\mathrm{Ca}^{2+}\right]_{\mathrm{i}}$, although previous studies $(19-22)$ have described the connection of CCBs and cellular calcium alternation in cancer cells.

In addition to their function as the channel blockers, CCBs are also suggested to affect growth hormone-releasing hormone receptors in cancers (21), the expression of P-glycoprotein (23), the function of breast cancer resistant protein $(17,24), \mathrm{Na}$ channel activity (25) and microRNA, resulting in alterations to cell proliferation and migration (8). In contrast to the activation of the miRNA-524-5P-BRI3-ERK pathway in MDA-MB-231 by nifedipine, there is a distinct pathway (AKt-eNOS-NO) present in MCF-7 following treatment with nifedipine. A previous study (26) revealed that eNOS and weak iNOS were expressed in MCF-7 cells and served an important role in cell proliferation. In general, NO can stimulate the proliferation and migration of epithelial cells in addition to gene profile expression (27).

Women comprise $\sim 1 / 3$ of all hypertension patients. A number of them may be suffering from, or are genetically predisposed to develop, breast cancer. Nifedipine may be dangerous for patients with breast cancers and indeed promotes breast cancer. Clinics should avoid administering nifedipine to women who suffer from breast cancer and hypertension.

\section{Acknowledgements}

This work was supported by research grants held by Y.G. from the 973 Project (grant nos. 2013CB531206 and 2012CB517803) and the National Natural Science Foundation of China (grant nos. 81170236, 31127001, 81570245 and 31221002).

\section{References}

1. Needleman $\mathrm{H}$ and Huff $\mathrm{J}$ : The international agency for research on cancer and obligate transparency. Lancet Oncol 6: 920-921, 2005.

2. Ellis MJ, Ding L, Shen D, Luo J, Suman VJ, Wallis JW, Van Tine BA, Hoog J, Goiffon RJ, Goldstein TC, et al: Whole-genome analysis informs breast cancer response to aromatase inhibition. Nature 486: 353-360, 2012.

3. Ruark E, Snape K, Humburg P, Loveday C, Bajrami I, Brough R, Rodrigues DN, Renwick A, Seal S, Ramsay E, et al: Mosaic PPM1D mutations are associated with predisposition to breast and ovarian cancer. Nature 493: 406-410, 2013.

4. Stephens PJ, Tarpey PS, Davies H, Van Loo P, Greenman C, Wedge DC, Nik-Zainal S, Martin S, Varela I, Bignell GR, et al: The landscape of cancer genes and mutational processes in breast cancer. Nature 486: 400-404, 2012.

5. Li W, Shi Q, Wang W, Liu J, Li Q and Hou F: Calcium channel blockers and risk of breast cancer: A meta-analysis of 17 observational studies. PLoS One 9: e105801, 2014. 
6. Li CI, Malone KE, Weiss NS, Boudreau DM, Cushing-Haugen KL and Daling JR: Relation between use of antihypertensive medications and risk of breast carcinoma among women ages 65-79 years. Cancer 98: 1504-1513, 2003.

7. Largent JA, Bernstein L, Horn-Ross PL, Marshall SF, Neuhausen S, Reynolds P, Ursin G, Zell JA, Ziogas A and Anton-Culver H: Hypertension, antihypertensive medication use, and breast cancer risk in the California teachers study cohort. Cancer Causes Control 21: 1615-1624, 2010.

8. Guo DQ, Zhang H, Tan SJ and Gu YC: Nifedipine promotes the proliferation and migration of breast cancer cells. PLoS One 9: e113649, 2014.

9. Ahr HJ, Bomhard E, Enzmann H, Karbe E, Mager H, Sander E and Schlüter G: Calcium channel blockers and the risk of cancer: A preclinical assessment. Cardiovasc Drugs Ther 12: 157-169, 1998.

10. Braun S, Boyko V, Behar S, Reicher-Reiss H, Laniado S, Kaplinsky E and Goldbourt U: Calcium channel blocking agents and risk of cancer in patients with coronary heart disease. Benzafibrate infarction prevention (BIP) study research group. J Am Coll Cardiol 31: 804-808, 1998.

11. Fryzek JP, Poulsen AH, Lipworth L, Pedersen L, Nørgaard M, McLaughlin JK and Friis S: A cohort study of antihypertensive medication use and breast cancer among Danish women. Breast Cancer Res Treat 97: 231-236, 2006.

12. Coleman CI,BakerWL,KlugerJ and White CM: Antihypertensive medication and their impact on cancer incidence: A mixed treatment comparison meta-analysis of randomized controlled trials. J Hypertens 26: 622-629, 2008.

13. Alfonzo-Méndez MA, Castillo-Badillo JA, Romero-Ávila MT, Rivera R, Chun J and García-Sáinz JA: Carboxyl terminus-truncated alpha1D-adrenoceptors inhibit the ERK pathway. Naunyn Schmiedebergs Arch Pharmacol 389: 911-920, 2016.

14. Soule HD, Vazguez J, Long A, Albert S and Brennan M: A human cell line from a pleural effusion derived from a breast carcinoma. J Natl Cancer Inst 51: 1409-1416, 1973

15. Tabei I, Nishiyama S, Yamashita S, Hashimoto H, Tachibana T, Uchida $\mathrm{K}$ and Ishikawa $\mathrm{H}$ : Establishment and characterization of HER2-positive cell line derived from pleural effusion of human breast scirrhous carcinoma Hum Cell 21: 105-112, 2008.

16. Cailleau R, Young R, Olivé M and Reeves WJ Jr: Breast tumor cell lines from pleural effusions. J Natl Cancer Inst 53: 661-674, 1974.
17. Zhang Y, Gupta A, Wang H, Zhou L, Vethanayagam RR, Unadkat JD and Mao Q: BCRP transports dipyridamole and is inhibited by calcium channel blockers. Pharm Res 22: 2023-2034, 2005.

18. Timcheva CV and Todorov DK: Does verapamil help overcome multidrug resistance in tumor cell lines and cancer patients? J Chemother 8: 295-299, 1996.

19. Correale P, Tagliaferri P, Celio L, Genua G, Montagnani S and Bianco AR: Verapamil upregulates sensitivity of human colon and breast cancer cells to LAK-cytotoxicity in vitro. Eur J Cancer 27: 1393-1395, 1991.

20. Fine RL, Patel J and Chabner BA: Phorbol esters induce multidrug resistance in human breast cancer cells. Proc Natl Acad Sci USA 85: 582-586, 1988

21. Garcia-Fernandez MO, Schally AV, Varga JL, Groot K and Busto R: The expression of growth hormone-releasing hormone $(\mathrm{GHRH})$ and its receptor splice variants in human breast cancer lines; the evaluation of signaling mechanisms in the stimulation of cell proliferation. Breast Cancer Res Treat 77: 15-26, 2003

22. Nie L, Oishi Y, Doi I, Shibata H and Kojima I: Inhibition of proliferation of MCF-7 breast cancer cells by a blocker of $\mathrm{Ca}(2+)$-permeable channel. Cell Calcium 22: 75-82, 1997.

23. Chung SY, Sung MK, Kim NH, Jang JO, Go EJ and Lee HJ: Inhibition of P-glycoprotein by natural products in human breast cancer cells. Arch Pharm Res 28: 823-828, 2005.

24. Zhou XF, Yang X, Wang Q, Coburn RA and Morris ME: Effects of dihydropyridines and pyridines on multidrug resistance mediated by breast cancer resistance protein: In vitro and in vivo studies. Drug Metab Dispos 33: 1220-1228, 2005.

25. Roger S, Le Guennec JY and Besson P: Particular sensitivity to calcium channel blockers of the fast inward voltage-dependent sodium current involved in the invasive properties of a metastastic breast cancer cell line. Br J Pharmacol 141: 610-615, 2004.

26. Loibl S, Bratengeier J, Farines V, von Minckwitz G, Spänkuch B, Schini-Kerth V, Nepveu F, Strebhardt K and Kaufmann M: Investigations on the inducible and endothelial nitric oxide synthases in human breast cancer cell line MCF-7-estrogen has an influence on e-NOS, but not on i-NOS. Pathol Res Pract 202: $1-7,2006$

27. Cheng RY, Basudhar D, Ridnour LA, Heinecke JL, Kesarwala AH, Glynn S, Switzer CH, Ambs S, Miranda KM and Wink DA: Gene expression profiles of NO- and $\mathrm{HNO}$-donor treated breast cancer cells: Insights into tumor response and resistance pathways. Nitric Oxide 43: 17-28, 2014. 